\title{
Evaluation of probiotic properties of Lactobacillus plantarum WLPL04 isolated from human breast milk
}

\author{
Meiling Jiang, ${ }^{*}$ Fen Zhang, ${ }^{*}$ Cuixiang Wan, $†$ Yonghua Xiong, $†$ Nagendra P. Shah,‡ Hua Wei, ${ }^{*} \dagger$ \\ and Xueying Tao* ${ }^{1}$ \\ *School of Life Sciences, Nanchang University, Nanchang 330031, P. R. China \\ †State Key Laboratory of Food Science and Technology, Nanchang University, Nanchang 330047, P. R. China \\ fFood and Nutritional Science, School of Biological Science, University of Hong Kong, Pokfulam Road, Hong Kong, P. R. China
}

\begin{abstract}
Lactobacillus plantarum WLPL04, a specific strain isolated from human breast milk, was investigated for its survival capacity (acid and bile salt tolerance, survival in simulated gastrointestinal tract, inhibition of pathogens, antibiotic susceptibility, yield of exopolysaccharides) and probiotic properties (antiadhesion of pathogens, protection from harmful effect of sodium dodecyl sulfate, and antiinflammatory stress on Caco-2 cells). The results showed that Lb. plantarum WLPL04 had broad-spectrum activity against gram-positive strains (Listeria monocytogenes CMCC54007, Bacillus cereus ATCC14579, and Staphylococcus aureus CMCC26003) and gram-negative strains (Pseudomonas aeruginosa MCC10104, Shigella sonnei ATCC25931, Enterobacter sakazakii ATCC29544, Salmonella typhimurium ATCC13311, and Escherichia coli O157:H7). Antibiotic susceptibility tests showed that $L b$. plantarum WLPL04 was susceptible to 8 of 14 antibiotics (e.g., erythromycin and nitrofurantoin) and resistant to 6 of 14 antibiotics (e.g., kanamycin and bacitracin). Lactobacillus plantarum WLPL04 was able to survive at $\mathrm{pH}$ 2.5 for $3 \mathrm{~h}$ and at $0.45 \%$ bile salt for $12 \mathrm{~h}$, suggesting that it can survive well in the gastrointestinal tract. In addition, the exopolysaccharide yield of $L b$. plantarum WLPL04 reached $426.73 \pm 65.56 \mathrm{mg} / \mathrm{L}$ at $24 \mathrm{~h}$. With strategies of competition, inhibition, and displacement, Lb. plantarum WLPL04 reduced the adhesion of $E$. coli O157:H7 (35.51\%), Sal. typhimurium ATCC 13311 (8.10\%), and Staph. aureus CMCC 26003 (40.30\%) on Caco-2 cells by competition, and subsequently by 59.80 , 62.50 , and $42.60 \%$, respectively, for the 3 pathogens through inhibition, and by $75.23,39.97$, and $52.88 \%$, respectively, through displacement. Lactobacillus plantarum WLPL04 attenuated the acute stress induced by
\end{abstract}

Received September 23, 2015.

Accepted November 15, 2015.

${ }^{1}$ Corresponding author: 1027txy@163.com sodium dodecyl sulfate on Caco-2 cells and significantly inhibited the expression of inflammatory cytokines (IL6 , IL-8 and tumor necrosis factor- $\alpha$ ) on Caco-2 cells but increased IL-10 expression in vitro compared with the Salmonella-treated group. In summary, Lb. plantarum WLPL04 from breast milk could be considered as a probiotic candidate for dairy products to promote human health.

Key words: Lactobacillus plantarum WLPL04, stress resistance, antiadhesion, antiinflammatory

\section{INTRODUCTION}

Numerous reports have demonstrated that probiotics from humans or fermented food can improve host health by maintaining the balance of flora in the gastrointestinal tract (GIT), preventing pathogen invasion, and activating the immune system (Parvez et al., 2006; Jankovic et al., 2010). Recently, Lactobacillus plantarum has been the subject of much scientific work due to its beneficial effects on the host, broad distribution in nature (e.g., pickles, sausage, and sourdough), and high commercial value for dairy products (da Silva Sabo et al., 2014; Kwak et al., 2014). Generally, most isolates of Lactobacillus plantarum from fermented food were evaluated for resistance to acidic environments and to bile salt juice, antagonism against pathogens, and adhesion on epithelial cells in vitro. Other works have focused on its immune-regulatory property (Zago et al., 2011), anticolitis effect (Lee et al., 2015), and potential beneficial adverse effect on inflammatory bowel disease (Mileti et al., 2009) in vitro.

Fermented vegetables (e.g., kimchi and pickles) containing Lactobacillus plantarum are routinely consumed by many people in China, Korea, and other Asian countries. It is hypothesized that this microorganism might exist in the mammary gland and breast milk of pregnant women who continuously consume foods fermented by Lactobacillus plantarum (Maldonado et al., 2010; Albesharat et al., 2011). In fact, human breast milk, as the first source of nutrition for the neonate, not only 
provides protection against different infectious diseases (Lara-Villoslada et al., 2007), but is also a reservoir for probiotics, such as bifidobacteria and lactic acid bacteria (LAB; Martín et al., 2003; Solís et al., 2010). A few reports have shown that LAB isolated from human milk are able to modulate both natural and acquired immune responses in mice and humans (Díaz-Ropero et al., 2007; Olivares et al., 2007), possess potent antibacterial activities to reduce the incidence and severity of infections (Olivares et al., 2006), exert efficacy to treat infectious mastitis (Arroyo et al., 2010), and play important roles in the infant (Maldonado et al., 2010).

In our previous work ( $\mathrm{Li}$ et al., 2014b), we demonstrated that metabolites of Lactobacillus plantarum R315 exert antioxidant and antibacterial activities, and that Lactobacillus plantarum ZDY2013 exhibits high stress resistance and possesses antibacterial properties. Moreover, we isolated several strains from breast milk and partially identified them as LAB by $16 \mathrm{~S}$ rDNA sequencing. Based on a protocol of in vitro antagonism tests against pathogens and challenging microorganisms in simulated GIT, to further determine whether Lb. plantarumWLPL04 inhibits pathogen adhesion on epithelium cells or affects inflammatory bowel disease by foodborne pathogenic bacteria, we used competition, inhibition, and displacement assays to ascertain the ideal strategy for $L b$. plantarum WLPL04 protection, and measured cytokines at the transcriptional level to understand the antiinflammatory effect of $L b$. plantarumWLPL04 on Caco-2 cells.

\section{MATERIALS AND METHODS}

\section{Bacterial Isolation and Identification}

Human breast milk samples were collected in sterile tubes by manual expression using sterile gloves after cleaning nipples and surrounding skin with sterile water and discarding the first drops. Samples were properly diluted and plated on de Man, Rogosa, and Sharpe (MRS) agar (Beijing Solarbio Science and Technology Co. Ltd., Beijing, China) plates containing $3 \% \mathrm{CaCO}_{3}$ (wt/vol). All plates were anaerobically incubated at $37^{\circ} \mathrm{C}$ for $48 \mathrm{~h}$. The isolates yielding a dissolving circle of $\mathrm{CaCO}_{3}$ were evaluated by Gram staining and microscopic observation to identify potential strains of LAB. Those strains were further screened by determination of the halo against Escherichia coli O157:H7 and Listeria monocytogenes. The selected isolates were then amplified by PCR with $16 \mathrm{~S}$ rDNA universal primers 27F and 1492R (shown as in Table 1). The amplicons were sequenced by Sangon Biotech Ltd. (Shanghai, China) and compared with sequences in the National
Center for Biotechnology Information (NCBI) database by using the BLAST algorithm to determine their classification (http://blast.ncbi.nlm.nih.gov/Blast.cgi).

\section{Antimicrobial Activity}

The antimicrobial activity of isolates against 8 foodborne pathogens was investigated by agar diffusion assay (Chen et al., 2014). Listeria monocytogenes CMCC54007, Pseudomonas aeruginosa MCC10104, Bacillus cereus ATCC14579, Shigella sonnei ATCC25931, Enterobacter sakazakii ATCC29544, Salmonella typhimurium ATCC13311, Staphylococcus aureus CMCC 26003, and E. coli O157:H7 were used as indicator strains to evaluate the antimicrobial spectrum of isolates. Cell-free supernatant of Lactobacillus strains was harvested by centrifugation $\left(7,500 \times g, 10 \mathrm{~min}, 4^{\circ} \mathrm{C}\right)$ and filtered through a $0.22-\mu \mathrm{m}$ Millipore filter (Merck Millipore Ltd., Tullagreen, Ireland). Indicator strains were cultured overnight to approximately $1 \times 10^{8} \mathrm{cfu} /$ $\mathrm{mL}$, and $100 \mu \mathrm{L}$ of each strain was spread on LuriaBertani agar plates. Then, $200 \mu \mathrm{L}$ of the lactobacilli cell-free supernatant was added to an Oxford cup (a stainless cylinder of outer diameter $7.8 \pm 0.1 \mathrm{~mm}$, inner diameter $6.0 \pm 0.1 \mathrm{~mm}$, and height $10.0 \pm 0.1 \mathrm{~mm}$ ), which was placed on the agar. After incubation for 12 $\mathrm{h}$, the diameter of the inhibition zone around the cup was measured. Three independent replicates were conducted for each experiment.

\section{Tolerance to Acid and Bile Salt}

Tolerance to acid and bile was assayed as reported previously (Huang et al., 2015) with minor modifications. To determine acid tolerance, overnight cultures of Lb. plantarum WLPL04 were inoculated in MRS broths $(1 \%, \mathrm{vol} / \mathrm{vol})$, which were adjusted to $\mathrm{pH} 4.5,3.5$, and 2.5 , with $\mathrm{HCl}(1.0 \mathrm{M})$. Cultures inoculated in nonacidi-

Table 1. Primers used in this study

\begin{tabular}{ll}
\hline Primer $^{1}$ & Oligonucleotide sequence $\left(5^{\prime}-3^{\prime}\right)$ \\
\hline $27 \mathrm{~F}$ & AGAGTTTGATCCTGGCTCAG \\
$1492 \mathrm{R}$ & TACGGCTACCTTGTTACGACTT \\
IL-6-F & AGCAAAGCAAAGAAACCGAT \\
IL-6-R & CAGCTCTGAGATGGCTTCAG \\
IL-8-F & AGGACAAGAGCCAGGAAGAA \\
IL-8-R & CAGAGCTGCAGAAATCAGGA \\
IL-10-F & AGGGAGGATGAGTGATTTGC \\
IL-10-R & AACTGGGAGGAACACTGACC \\
TNF- $\alpha-F$ & TTTGATCCCTGACATCTGGA \\
TNF- $\alpha-R$ & GGCCTAAGGTCCACTTGTGT \\
$\beta-2-m i c r o g l o b u l i n-F$ & GGCTATCCAGCGTACTCCAAA \\
$\beta-2-$ microglobulin-R & CGGCAGGCATACTCATCTTTTT \\
\hline${ }^{1} \mathrm{~F}=$ forward; $\mathrm{R}=$ reverse. &
\end{tabular}


fied MRS (pH 6.5) served as controls. Tolerance to bile salt was tested by inoculating the cultures into MRS broth $(1 \%$, vol/vol) supplemented with $0,0.15,0.30$, and $0.45 \%$ (wt/vol) of oxgall (Yuanye Bio-Technology Ltd., Shanghai, China). Cultures were then incubated at $37^{\circ} \mathrm{C}$ for $0,3,6,12$, and $24 \mathrm{~h}$. The acid and bile salt tolerance of the cells were assessed by enumerating viable cells on MRS agar plates. The experiments were performed in triplicate.

\section{Resistance to GIT}

The survival of $L b$. plantarum WLPL04 during passage through a chemically simulated GIT was determined as reported by Nikolic et al. (2012), with some modifications. Briefly, cells of Lb. plantarum WLPL04 from 24-h MRS cultures were harvested by centrifugation $\left(7,500 \times g, 10 \mathrm{~min}, 4^{\circ} \mathrm{C}\right)$, washed twice with $0.85 \%$ $\mathrm{NaCl}$, resuspended in gastric juice $(\mathbf{G J} ; 125 \mathrm{mM} \mathrm{NaCl}$, $7 \mathrm{~m} M \mathrm{KCl}, 45 \mathrm{~m} M \mathrm{NaHCO}_{3}, 0.30 \%$ pepsin adjusted to $\mathrm{pH} 2$ with $\mathrm{HCl}$ ) containing $10 \%$ (wt/vol) skim milk, and incubated for $90 \mathrm{~min}$ at $37^{\circ} \mathrm{C}$ in aerobic conditions. Afterward, bacterial suspensions were centrifuged $(7,500$ $\times g, 10 \mathrm{~min}$ ), resuspended in duodenal juice (DJ; $1 \%$ bovine bile adjusted with $10 \mathrm{M} \mathrm{NaOH}$ to $\mathrm{pH} 8.0$ ), and incubated for $10 \mathrm{~min}$ at $37^{\circ} \mathrm{C}$ in an anaerobic chamber. Then, the cells were centrifuged again, resuspended in intestinal juice $[\mathbf{I J} ; 0.30 \%$ bovine bile, $0.1 \%$ pancreas acetone powder porcine Type I (Sigma, St. Louis, MO), $\mathrm{pH}$ 8.0], and incubated for $120 \mathrm{~min}$ at $37^{\circ} \mathrm{C}$ in anaerobic conditions. Two samples were collected during the IJ challenge, after 60 and $120 \mathrm{~min}$. Viable cell counts were obtained from the initial cultures and after each of the GJ, DJ, and IJ challenges. Cells were serially diluted in $0.01 M$ PBS and plated on MRS agar. Plates were incubated for $48 \mathrm{~h}$ at $37^{\circ} \mathrm{C}$, and results were expressed as $\log$ colony-forming units per milliliter. Experiments were carried out in triplicate.

\section{Production of Exopolysaccharides}

The exopolysaccharides (EPS) from cell-free culture supernatant were extracted and detected by methods previously reported (Li et al., 2014a). Briefly, Lb. plantarum WLPL04 was inoculated (1\%) in $100 \mathrm{~mL}$ of MRS broth and cultured anaerobically at $37^{\circ} \mathrm{C}$. Bacterial cells were removed by centrifugation at $4,000 \times g$ for $10 \mathrm{~min}$. The EPS in the cell-free culture supernatant was precipitated with ethanol $(80 \% \mathrm{vol} / \mathrm{vol})$ overnight and then recovered by centrifugation at $8,000 \times g$ for $20 \mathrm{~min}$, at $4^{\circ} \mathrm{C}$. The precipitate was collected and dissolved in distilled water. Proteins were removed with Sevag solution (chloroform: $n$-butanol $=4: 1$ ) followed by centrifugation $(8,000 \times g, 10 \mathrm{~min})$. Then, the collected EPS was dialyzed against distilled water for 24 $\mathrm{h}$ at $4^{\circ} \mathrm{C}$. The concentration of EPS was determined by the phenol-sulfuric acid assay method (Dubois et al., 1956) using glucose as standard.

\section{Antibiotic Susceptibility Assay}

The resistance of $L b$. plantarum WLPL04 to antibiotics was determined by the disc diffusion method (Tan et al., 2013). In brief, Lb. plantarum WLPL04 was grown in MRS broth overnight at $37^{\circ} \mathrm{C}$ in anaerobic conditions, and $100 \mu \mathrm{L}$ of each culture $\left(10^{7} \mathrm{cfu} /\right.$ $\mathrm{mL}$ ) was swabbed on MRS agar plates. Antibiotic discs (Bio-Kont Co. Ltd., Wenzhou, China) were placed on the surface of inoculated plates. The concentrations of the tested antibiotics are as in Table 2. The plates were incubated anaerobically at $37^{\circ} \mathrm{C}$ for $24 \mathrm{~h}$. The inhibition zone after incubation was measured and interpreted as

Table 2. The antibiotic susceptibility of Lactobacillus plantarum WLPL041 (means \pm SD of 3 trials)

\begin{tabular}{|c|c|c|c|c|}
\hline Class & Antibiotic & Content & $\begin{array}{l}\text { Diameter of inhibition } \\
\text { zone }(\mathrm{mm})\end{array}$ & Sensitivity $^{1}$ \\
\hline \multirow[t]{2}{*}{ Macrolide } & Erythromycin & $15 \mu \mathrm{g}$ & $23.84 \pm 0.19$ & $\mathrm{~S}$ \\
\hline & Rifampicin & $5 \mu \mathrm{g}$ & $0.00 \pm 0.05$ & $\mathrm{R}$ \\
\hline \multirow[t]{3}{*}{ Aminoglycoside } & Streptomycin & $10 \mu \mathrm{g}$ & $3.84 \pm 0.34$ & $\mathrm{I}$ \\
\hline & Gentamicin & $10 \mu \mathrm{g}$ & $4.07 \pm 0.14$ & $\mathrm{I}$ \\
\hline & Kanamycin & $30 \mu \mathrm{g}$ & $0.00 \pm 0.05$ & $\mathrm{R}$ \\
\hline Nitrofurans & Nitrofurantoin & $300 \mu \mathrm{g}$ & $24.47 \pm 0.93$ & $\mathrm{~S}$ \\
\hline Tetracyclines & Tetracycline & $30 \mu \mathrm{g}$ & $18.04 \pm 0.09$ & I \\
\hline Amphenicols & Chloramphenicol & $30 \mu \mathrm{g}$ & $23.87 \pm 0.24$ & $\mathrm{~S}$ \\
\hline \multirow[t]{2}{*}{$\beta$-Lactams } & Amoxicillin & $10 \mu \mathrm{g}$ & $23.14 \pm 0.12$ & $\mathrm{~S}$ \\
\hline & Penicillin & $10 \mathrm{U}$ & $23.34 \pm 0.17$ & $\mathrm{~S}$ \\
\hline \multirow[t]{2}{*}{ Glycopeptide } & Bacitracin & $0.04 \mathrm{U}$ & $0.00 \pm 0.05$ & $\mathrm{R}$ \\
\hline & Polymyxin B & $30 \mu \mathrm{g}$ & $0.00 \pm 0.05$ & $\mathrm{R}$ \\
\hline \multirow[t]{2}{*}{ Quinolones } & Ciprofloxacin & $5 \mu \mathrm{g}$ & $0.00 \pm 0.05$ & $\mathrm{R}$ \\
\hline & Nalidixic acid & $30 \mu \mathrm{g}$ & $0.00 \pm 0.05$ & $\mathrm{R}$ \\
\hline
\end{tabular}

${ }^{1} \mathrm{~S}=$ susceptible $\mathrm{I}=$ intermediate $; \mathrm{R}=$ resistance. 
susceptible, intermediate, or resistant according to the instructions for the antibiotic discs (Bio-Kont Co. Ltd.)

\section{Adhesion Assay}

Cell Culture. The human intestinal epithelial cell line Caco-2 (purchased from the cell bank of Chinese Academy of Sciences, Shanghai, China) was used to assess the adhesion ability of selected strains. The Caco-2 cells were in Dulbecco's modified Eagle medium (DMEM) supplemented with $10 \%$ (vol/vol) heatinactivated fetal bovine serum (ExCell Bio Co. Ltd., Shanghai, China) and a standard mixture of antibiotics (100 U/mL penicillin, $100 \mu \mathrm{g} / \mathrm{mL}$ streptomycin; Beijing Solarbio Science and Technology Co. Ltd.) in an atmosphere of $5 \%$ (vol/vol) $\mathrm{CO}_{2}$ at $37^{\circ} \mathrm{C}$. The Caco-2 cells were maintained in $75-\mathrm{cm}^{2}$ cell culture flasks and differentiated into enterocytes after 15 to 20 d; the medium was replaced every $2 \mathrm{~d}$.

Adhesion. Adhesion assays were carried out in a 35-mm-diameter 6-well plate. A Caco-2 cell monolayer was washed twice with PBS ( $\mathrm{pH} 7.4$ ) to remove antibiotics before use. Then, $0.1 \mathrm{~mL}$ (about $10^{7} \mathrm{cfu} / \mathrm{mL}$ ) of Lb. plantarum WLPL04 or pathogen suspension was added at a Caco- 2 cell:bacteria ratio of 1:10. After 90 min of incubation at $37^{\circ} \mathrm{C}$ under $5 \% \mathrm{CO}_{2}$ atmosphere, wells were gently washed 3 times with PBS solution to remove unbound bacteria. Caco-2 cells and adhered bacteria were then detached with an EDTA-trypsin solution (Sigma-Aldrich), and the attached bacteria were counted by plating in MRS agar. Adhesion was expressed as the percentage of bacteria adhered with respect to total number of bacteria added. Assays were performed in triplicate.

Effects on Adhesion of Pathogens to Caco-2 Cells. The ability of Lb. plantarum WLPL04 to inhibit the adhesion of pathogens (Sal. typhimurium ATCC13311, Staph. aureus CMCC26003, and E. coli O157:H7) to Caco-2 cells was investigated according to the method reported by Dhanani et al. (2011). Briefly, 3 different types of experiments were performed: (1) competitive assay; that is, simultaneously incubating Caco-2 cells with $L b$. plantarum WLPL04 and each of the pathogens for $90 \mathrm{~min}$; (2) inhibition assay; that is, pre-incubating Caco- 2 cells with the $L b$. plantarum WLPL04 for $90 \mathrm{~min}$, and then adding each of the pathogens and incubating for another $90 \mathrm{~min}$; (3) displacement assay; that is, pre-incubating Caco-2 cells with each of the pathogens for $90 \mathrm{~min}$, and then adding Lb. plantarum WLPL04 and further incubating for 90 min. Competitiveness was calculated as the percentage of adhesion of pathogens added in combination with Lb. plantarum WLPL04 relative to pathogen-bound bacteria in the absence of $L b$. plantarum WLPL04 (con- trol). The inhibition of the adhesion of pathogens was expressed as a percentage using the following formula: Inhibition of adhesion $=100 \times(1-\mathrm{T} 1 / \mathrm{T} 2)$, where T1 and T2 are the percentage of adhesion by pathogens cells in the presence and absence of $L b$. plantarum WLPL04, respectively. Displacement of pathogens was expressed as the percentage of adhesion by pathogen cells in the presence and absence of Lb. plantarum WLPL04 strain, as described above.

\section{Protection Against Inflammatory Stress}

Inflammatory stress was induced by treating the Caco-2 cells with SDS, which was added into DMEM at a final concentration of $0.05 \%$ (wt/vol). Lactobacillus plantarum WLPL04 $\left(10^{7} \mathrm{cfu} / \mathrm{mL}\right)$ was resuspended in DMEM and added into each well of a 96-well plate. The residual cell viability at $24 \mathrm{~h}$ was evaluated by 3-(4, 5-dimethylthiazol-2-yl)-2,5-diphenyltetrazolium bromide (MTT) assay (Presti et al., 2015). Cells were washed with sterile PBS, and then $0.05 \%$ (wt/vol) MTT in DMEM was added into each well and incubated for $4 \mathrm{~h}$. After incubation, the medium was removed and replaced with dimethyl sulfoxide, and shaken for $10 \mathrm{~min}$. The formazan produced was measured as absorbance at $490 \mathrm{~nm}\left(\mathrm{~A}_{490}\right)$ by using a microplate reader. The results were calculated as $\left(\mathrm{A}_{490}\right.$ of treated cells $-\mathrm{A}_{490}$ untreated cells) $/ \mathrm{A}_{490}$ untreated $\times 100$.

\section{Quantification of Cytokine in Caco-2 Cultures}

The levels of IL-6, IL-8, and tumor necrosis factor $\alpha$ (TNF- $\boldsymbol{\alpha})$ as pro-inflammatory cytokines and IL-10 as anti-inflammatory cytokine in Caco-2 cells were determined as follows: $1 \times 10^{6}$ cells were treated with $1 \mathrm{~mL}$ of DMEM containing Sal. typhimurium ATCC 13311 $\left(10^{7} \mathrm{cfu} / \mathrm{mL}\right)$ alone or with $L b$. plantarum WLPL04 $\left(10^{7} \mathrm{cfu} / \mathrm{mL}\right)$ for $4 \mathrm{~h}$. Untreated Caco-2 cells were used as control. At the end of incubation, the medium was removed and replaced with fresh DMEM containing antibiotic, and cells were incubated for a further 20 $\mathrm{h}$ (Finamore et al., 2014). The transcription level of cytokines in Caco-2 cells was evaluated by quantitative PCR. Total RNA was isolated from cells using TRIzol Reagent (Trans, Beijing, China). Single-strand cDNA was synthesized from the total RNA using the PrimeScript RT reagent kit with gDNA Eraser for quantitative PCR (Takara, Shiga, Japan) according to the manufacturer's instructions. The PCR was conducted with a SYBR Premix Ex Taq II (TliRNaseH Plus; Takara) and ABI 7500 Fast real-time PCR system (Applied Biosystems, Foster City, CA). The cycling profile used for quantitative PCR was as follows: a preheating step for enzyme activation at $95^{\circ} \mathrm{C}$ for $1 \mathrm{~min}$, followed 
by 40 cycles of $95^{\circ} \mathrm{C}$ for $15 \mathrm{~s}, 58^{\circ} \mathrm{C}$ for $60 \mathrm{~s}$, and $72^{\circ} \mathrm{C}$ for $15 \mathrm{~s}$. The relative transcription level was calculated using the $2^{-\Delta \Delta \mathrm{Ct}}$ method (Feng et al., 2010). The $\beta-2-$ microglobulin gene was used as a reference gene. Oligonucleotides specific to IL-6, IL-8, IL-10, and TNF- $\alpha$ (shown in Table 1) were used for quantitative PCR.

\section{Statistical Analysis}

Triplicate data were expressed as mean \pm standard deviation. The SPSS 13.0 software (SPSS Inc., Chicago, IL) was used to perform statistical analyses by means of independent one-way ANOVA tests. The multiple comparison of each test was assessed by least significant difference (LSD) test $(P<0.05)$.

\section{RESULTS}

\section{Isolation, Identification of Lb. plantarum WLPL04, and Antimicrobial Activity and Susceptibility}

Eighteen isolates from human breast milk were identified as potential lactobacilli by organic acid yield testing in modified MRS plates containing $\mathrm{CaCO}_{3}$ and microscopic observation. Those isolates were subjected to preliminary evaluation for their antimicrobial activity by using E. coli $\mathrm{O} 157: \mathrm{H} 7$ and Listeria monocytogenes as model strains of pathogens. Subsequently, one strain, named $L b$. plantarum WLPL04, was screened out for its best antagonistic properties against Listeria monocytogenes CMCC54007 and E. coli O157:H7. The antimicrobial spectrum of $L b$. plantarum WLPL04 was investigated by using 8 pathogens as targets. As shown in Figure 1, Lb. plantarum WLPL04 demonstrated its broad activity against all tested gram-positive (L. monocytogenes CMCC54007, B. cereus ATCC14579, and Staph. aureus CMCC26003) and gram-negative ( $P$. aeruginosa MCC10104, Shigella sonnei ATCC25931, Ent. sakazakii ATCC29544, Sal. typhimurium ATCC13311, and E. coli $\mathrm{O} 157: \mathrm{H} 7)$ strains, with halos ranging from $12.6 \pm 0.46 \mathrm{~mm}$ on $B$. cereus ATCC14579 to $33.07 \pm$ $0.15 \mathrm{~mm}$ on P. aeruginosa MCC10104.

Antibiotic susceptibility was an important index for the safety of LAB before application. As shown in Table 2, Lb. plantarum WLPL04 was susceptible to macrolides (e.g., erythromycin), nitrofurans (e.g., nitrofurantoin), amphenicols (e.g., chloramphenicol), and $\beta$-lactams (e.g., amoxicillin and penicillin); and showed intermediate sensitivity to tetracyclines and aminoglycoside (e.g., streptomycin and gentamicin). In contrast, Lb. plantarum WLPL04 was resistant to rifampicin, kanamycin, glycopeptide (e.g., bacitracin, polymyxin B), and quinolones (e.g., ciprofloxacin, nalidixic acid).

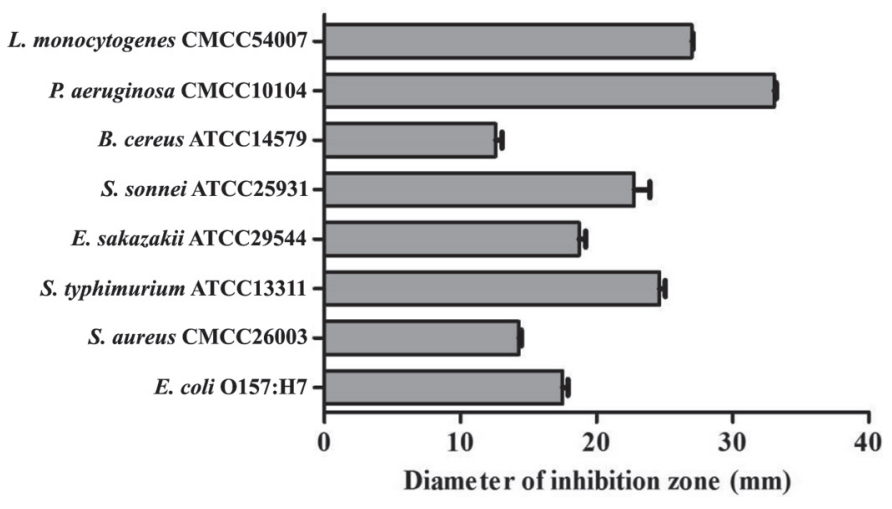

Figure 1. Antibacterial activity of supernatants of overnight culture of Lactobacillus plantarum WLPL04 against 8 foodborne pathogens. Data of triplicate trials are expressed as mean \pm SD.

\section{Growth and EPS Production of Lb. plantarum WLPLO4}

In our previous work (Li et al., 2014b), we determined that inhibition of pathogens might result not only from low $\mathrm{pH}$ but also from primary metabolite EPS. Thus, EPS yields, viable cell counts, and $\mathrm{pH}$ were chosen as parameters to monitor in the current study. As shown in Figure 2, Lb. plantarum WLPL04 reached stationary phase $12 \mathrm{~h}$ after inoculation; the cell count increased by $2.17 \log \mathrm{cfu} / \mathrm{mL}$ from the initial inoculate of 6.53 $\log \mathrm{cfu} / \mathrm{mL}$, and then maintained a stable biomass and low $\mathrm{pH}$ to 3.75 at $36 \mathrm{~h}$. The EPS yield of $L b$. plantarum WLPL04 peaked at $426.73 \pm 65.56 \mathrm{mg} / \mathrm{L}$ at $24 \mathrm{~h}$.

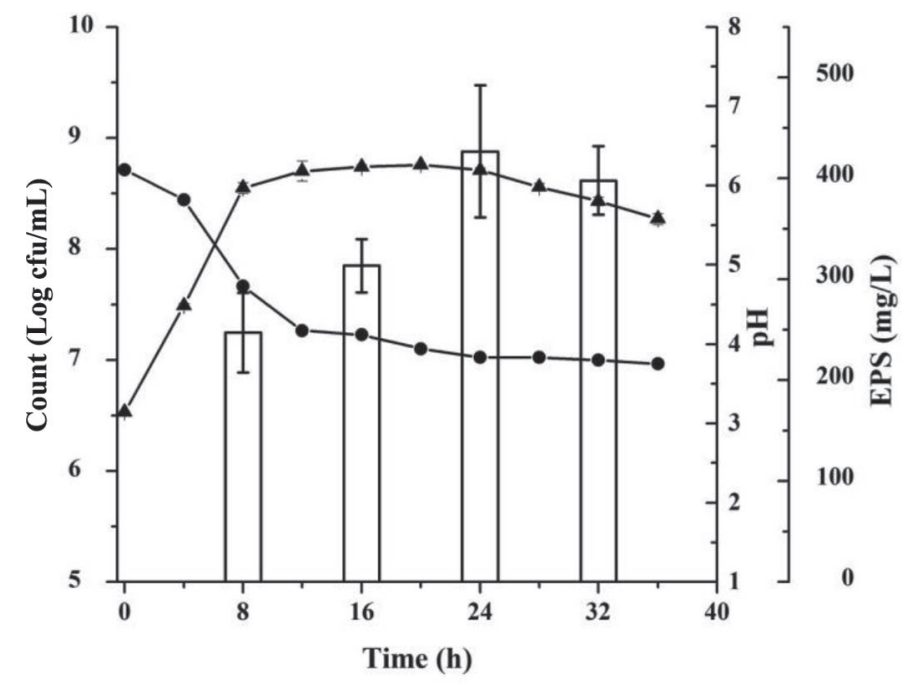

Figure 2. Kinetics of growth, $\mathrm{pH}$ value of fermentation culture, and exopolysaccharide (EPS) production by Lactobacillus plantarum WLPL04 in de Man, Rogosa, and Sharpe medium. Shown are the amounts of EPS produced (bar graph), bacterial cell counts $(\mathbf{\Lambda})$, and $\mathrm{pH}$ of fermentation culture $(\mathbf{)})$. Data of triplicate trials are expressed as mean $\pm \mathrm{SD}$. 


\section{Acid and Bile Salt Tolerance and Survival in Simulated GIT}

To evaluate the antistress ability of $L b$. plantarum WLPL04, we determined the survival of $L b$. plantarum WLPL04 under different acidic $\mathrm{pH}$ and bile salt conditions. As shown in Figure 3A, Lb. plantarum WLPL04 maintained stable growth at $\mathrm{pH} 4.5$ and a static state at $\mathrm{pH} 3.5$ from 0 to $24 \mathrm{~h}$, but cell count by $2.34 \log \mathrm{cfu} /$ $\mathrm{mL}$ after $6 \mathrm{~h}$ at $\mathrm{pH} 2.5$. At 6 h, Lb. plantarum WLPL04 was sensitive to $\mathrm{pH}$ from 4.5 to 2.5 , with a decreased survival rate of cells from 7.69 to $4.22 \mathrm{log} \mathrm{cfu} / \mathrm{mL}$ (Figure $3 \mathrm{~A}$ inset).

The effect of bile salt on viable counts of $L b$. plantarum WLPL04 is shown in Figure 3B; cell counts decreased slightly with $0.15 \%$ bile salt, and reduced by 0.83 and $1.17 \log \mathrm{cfu} / \mathrm{mL}$ with 0.30 and $0.45 \%$ bile salts, respectively, for $6 \mathrm{~h}$. A significant reduction $(P<$ $0.05)$ in cell count occurred at $24 \mathrm{~h}$ in both the 0.30 and $0.45 \%$ bile salt treatments.

To further evaluate the survival capability of $L b$. plantarum WLPL04, a simulated gastric-duodenalintestinal transit system was set up. As shown in Figure 4, the count of $L b$. plantarum WLPL04 decreased by 0.40 and $1.07 \log \mathrm{cfu} / \mathrm{mL}$, from initial values of $6.09 \times$ $10^{8} \mathrm{cfu} / \mathrm{mL}$ to $2.42 \times 10^{8} \mathrm{cfu} / \mathrm{mL}$ and $5.18 \times 10^{7} \mathrm{cfu} /$ $\mathrm{mL}$, respectively, after the GJ and DJ (1\% bile salt) challenges. After exposure to IJ, which consisted of $0.30 \%$ bile and pancreatic enzymes, bacterial viability increased up to $1.30 \times 10^{8} \mathrm{cfu} / \mathrm{mL}$.

\section{Adhesion and Antiadhesion Against Pathogens}

Adhesion and antiadhesion of pathogenic microorganisms are the most important biological properties for probiotic selection. Using the Caco-2 cell line as a model, we approached the antagonistic effect of adhesion of Lb. plantarum WLPL04 against E. coli O157:H7, Sal. typhimurium ATCC13311, and Staph. aureus CMCC26003 with 3 strategies - competition, inhibition, and displacement. As shown in Figure 5, under competition, the adhesion ratio of $E$. coli $\mathrm{O} 157: \mathrm{H} 7$, Sal. typhimurium ATCC13311, and Staph. aureus CMCC26003 was reduced by 35.51, 8.10, and $40.30 \%$, respectively. Under inhibition, that ratio was reduced by $59.81,62.50$, and $42.60 \%$, respectively, and under displacement, by $75.23,39.97$, and $52.88 \%$, respectively.

\section{Protection from Harmful Effects of SDS}

Probiotics usually protect against oxidative stress. To investigate that potential in $L b$. plantarum WLPL04, we induced an acute stress state of Caco-2 cells by SDS (a detergent) as a model for the protection of this

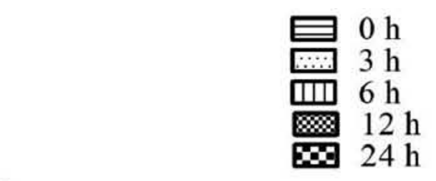

A
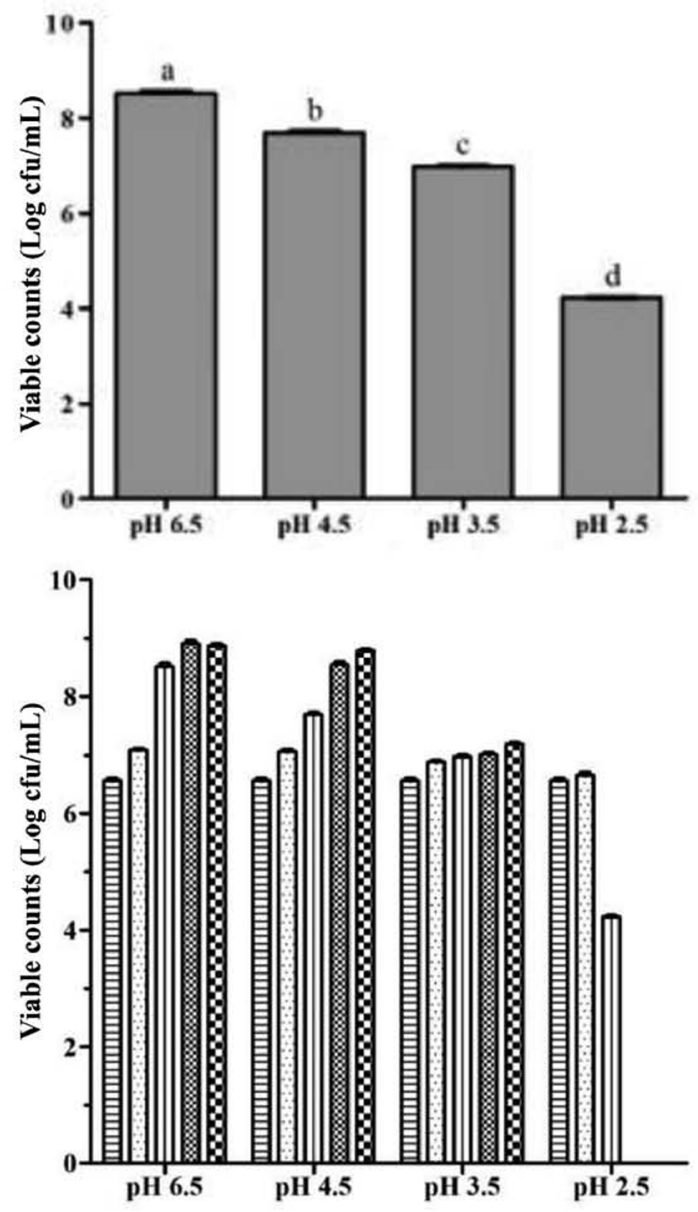

B

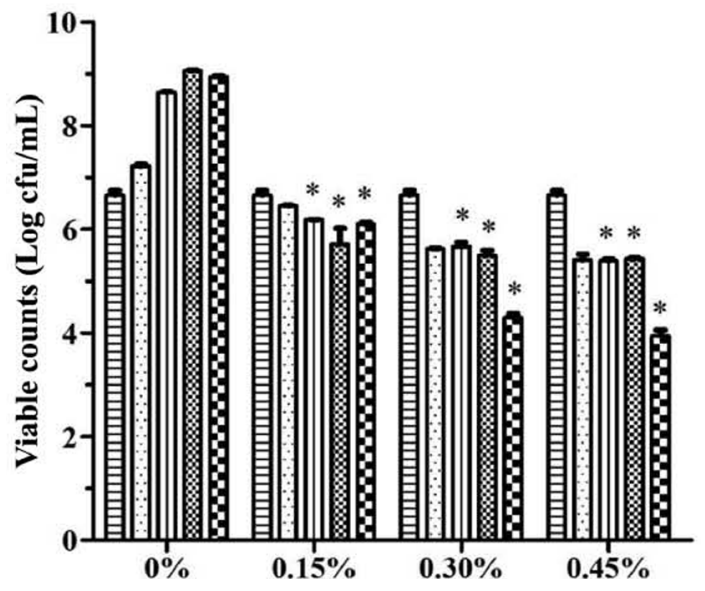

Figure 3. The survival capacity of Lactobacillus plantarum WLPL04 challenged for resistance to acid (A) and bile salt (B). Data of triplicate trials are expressed as mean $\pm \mathrm{SD} .{ }^{*} P<0.01$; all conditions are compared with respective controls. 


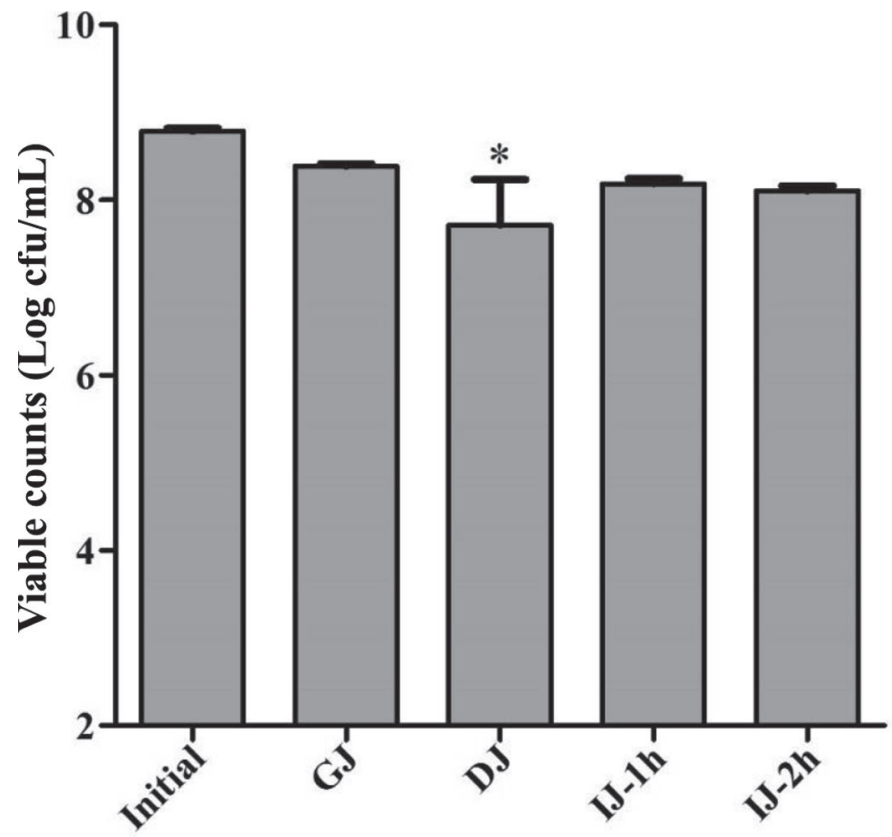

Figure 4. Survival of Lactobacillus plantarum WLPL04 (10\% skim milk) through simulated gastrointestinal tract (GIT). Viable counts were obtained at each sampling point. GJ = gastric juice, DJ = duodenal juice, $\mathrm{IJ}=$ intestinal juice. Data of triplicate trials are expressed as mean \pm SD. All data were compared with initial value; ${ }^{*} P<0.05$.

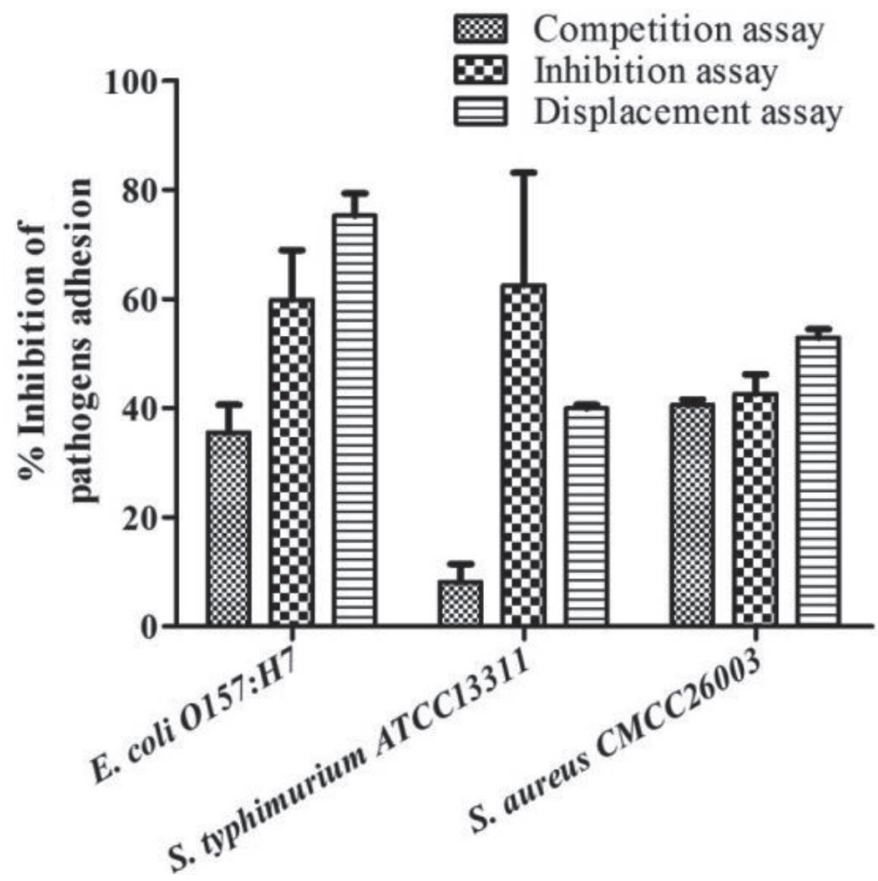

Figure 5. Antiadhesion assays (competition, inhibition, and displacement) of Lactobacillus plantarum WLPL04 against Escherichia coli O157:H7, Salmonella typhimurium ATCC13311, and Staphylococcus aureus CMCC26003. Data of triplicate trials are expressed as mean \pm $\mathrm{SD}$.

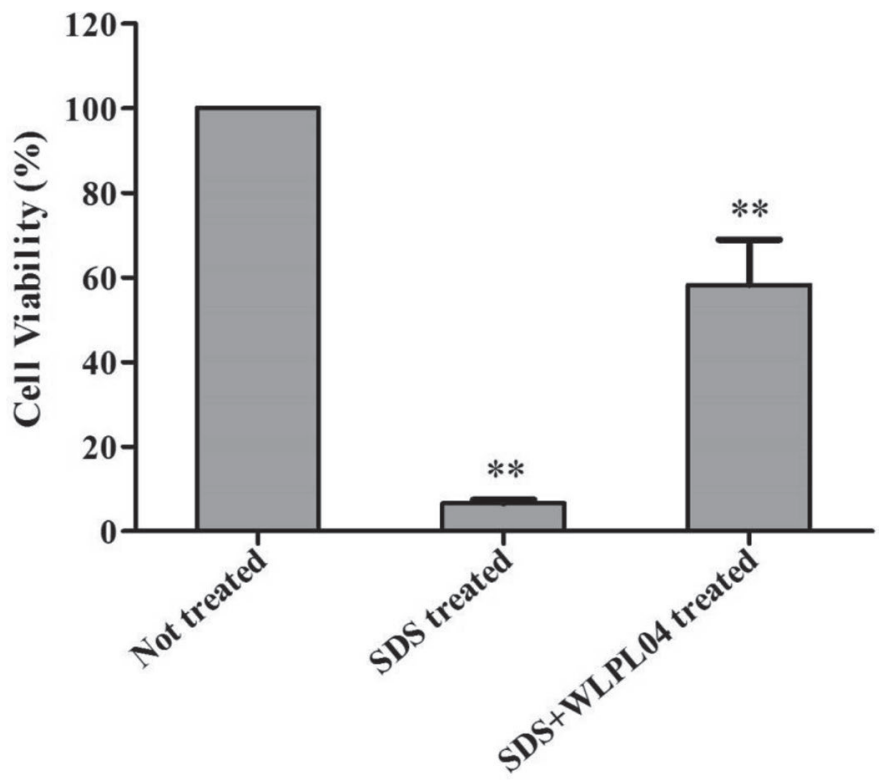

Figure 6. Protective effect of Lactobacillus plantarum WLPL04 on Caco-2 cells in the presence of SDS as irritant agent after $24 \mathrm{~h}$; nontreated cells were used as negative control. Residual cell viability was measured by MTT assay and expressed as percentage (\%). Data of triplicate trials are expressed as mean \pm SD. All the data were compared with nontreated group; ${ }^{* *} P<0.01$.

strain. As shown in Figure 6, Lb. plantarum WLPL04 significantly improved the viability of Caco-2 cells $(P$ $<0.01$ ), by 8.79 -fold, compared with the SDS-treated group, and thus prevented the adverse effect (oxidation damage on cells) of SDS.

\section{Protection from Salmonella-Induced Inflammation}

We investigated the antiinflammatory effect of $L b$. plantarum WLPL04 on Caco-2 cells by measuring the expression level of mRNA of 4 cytokines, using Salmonella typhimurium ATCC13311 as stimulator. As shown in Figure 7, under stimulation of Salmonella typhimurium ATCC13311, mRNA expression of IL-6, IL-8, IL-10, and TNF- $\alpha$ showed a tendency to increase. When compared with the S. typhimurium ATCC13311treated group, Lb. plantarum WLPL04 alone decreased the proinflammatory cytokines (IL-6, IL-8, and TNF- $\alpha$ ) and increased the antiinflammatory cytokine IL-10 ( $P$ $<0.01)$. In contrast, a mixture of $L b$. plantarum and S. typhimurium had the same potential to decrease the expression of all proinflammatory cytokines mentioned above but had no effect on IL-10.

\section{DISCUSSION}

Recently, Lb. plantarum has attracted increasing scientific work because of its wide range of health- 
A

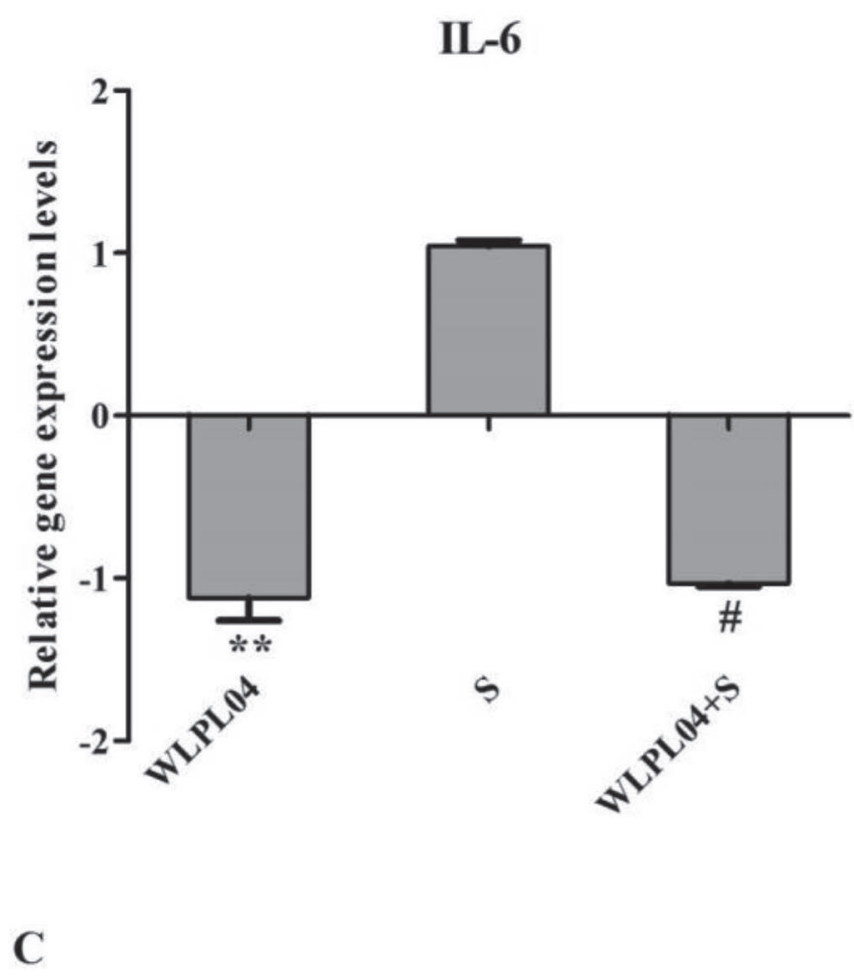

IL-10

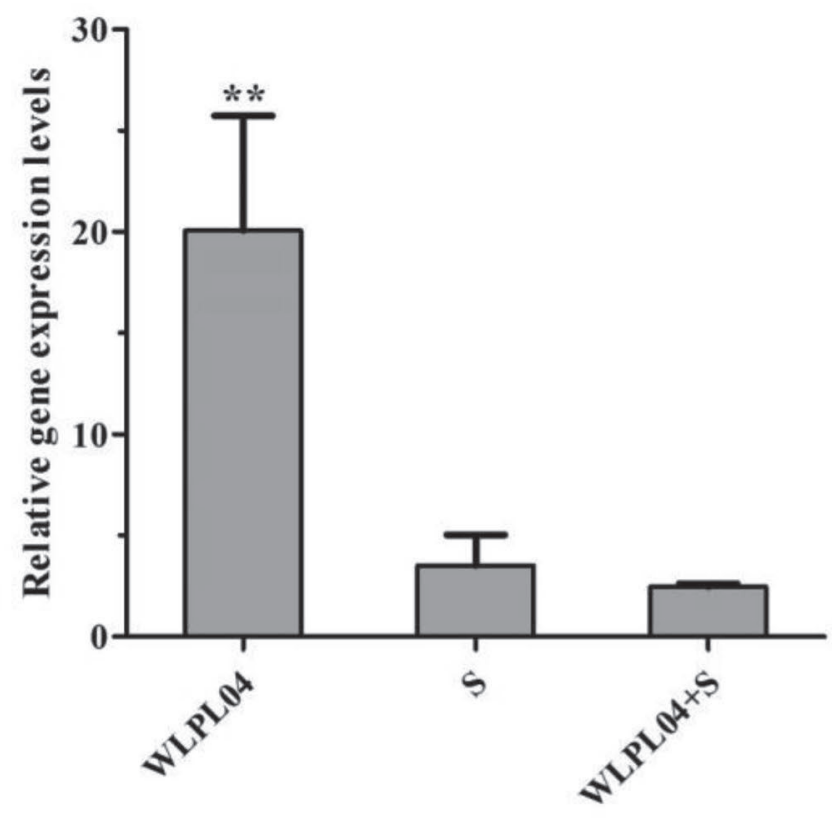

B

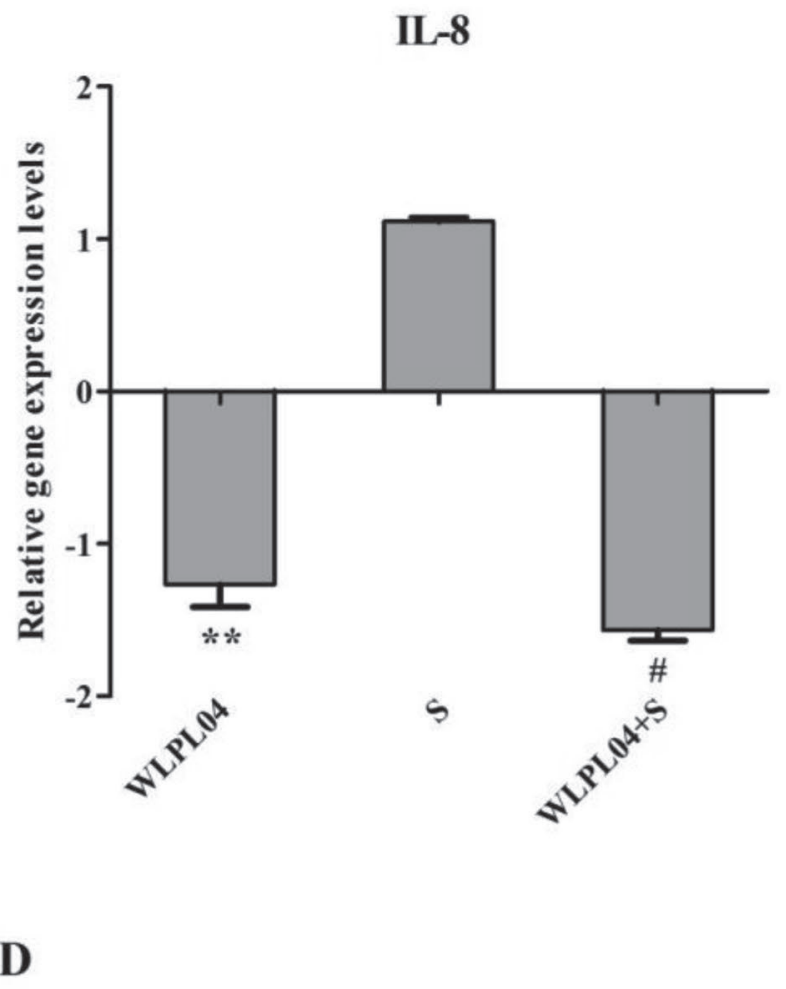

TNF- $\alpha$

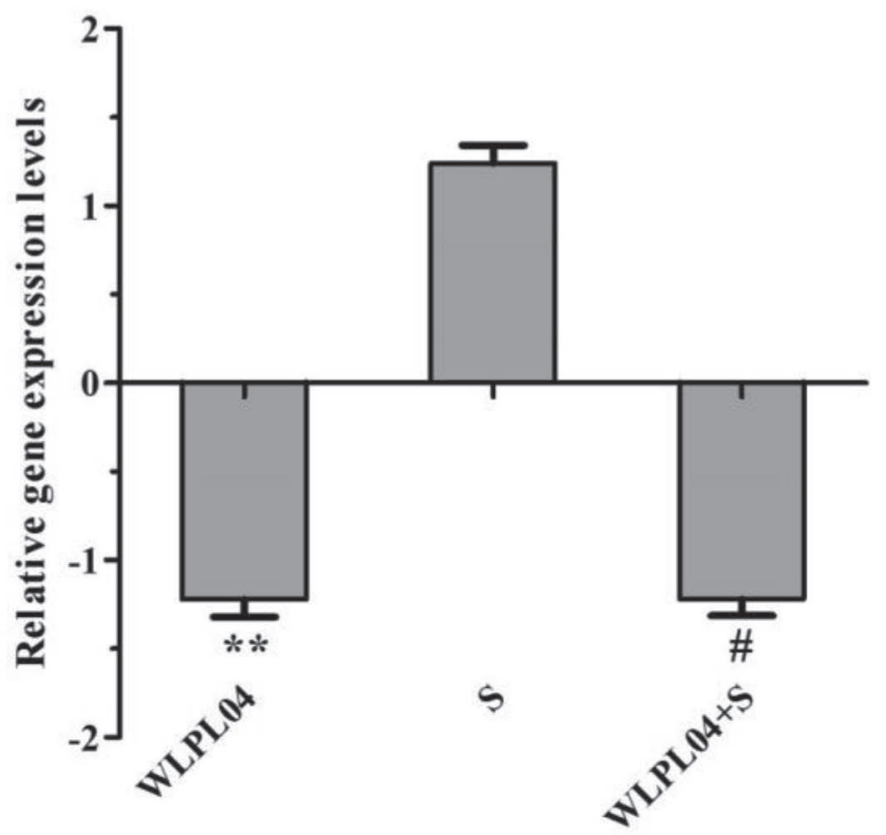

Figure 7. Effect of Lactobacillus plantarum WLPL04 on cytokine expression in Caco-2 cells: (A) IL-6, (B) IL-8, (C) IL-10, and (D) tumor necrosis factor- $\alpha$ (TNF- $\alpha$ ). Nontreated cells were used as control. Groups of $L b$. plantarum WLPL04 (WLPL04) and a mixture of $L b$. plantarum WLPL04 and Salmonella typhimurium ATCC1331 (WLPL04 $+\mathrm{S}$ ) were compared with S. typhimurium ATCC13311 $(\mathrm{S})$. $* * P<0.01, \# P<$ 0.01. Data of triplicate trials are expressed as mean \pm SD. 
promoting effects. In our previous work, $L b$. plantarum isolated from homemade acid beans demonstrated high stress resistance at either the physiological or molecular level and possessed antibacterial and gut microbiota modulation properties (Huang et al., 2015). In the current study, Lb. plantarum WLPL04 was systematically evaluated for its in vitro resistance against extreme acid and bile salts, digestion of enzyme, antagonistic effect against the adhesion of 3 pathogens (E. coli O157:H7, Sal. typhimurium ATCC13311, and Staph. aureus CMCC26003), and antiinflammatory effect on Sal. typhimurium-induced cytokine expression in a Caco-2 cell line. Our results indicated that Lb. plantarum WLPL04 can pass through the gastric environment, survive well in the intestinal tract, and protect epithelial cells from infection by pathogenic microorganisms. In part, our findings are consistent with reports that Lactobacillus amylovorus inhibits the inflammation of intestinal Caco-2 cells triggered by enterotoxigenic pathogens (Finamore et al., 2014), and that Lactobacillus paracasei modulates Salmonellainduced inflammation of Caco-2 cells (Bermudez-Brito et al., 2015).

In the in vitro inhibition tests, we demonstrated that Lb. plantarum WLPL04 achieved ideal antagonistic effect against 8 common pathogens (i.e., $P$. aeruginosa MCC10104, B. cereus ATCC14579, Sh. sonnei ATCC25931, Ent. sakazakii ATCC29544, Sal. typhimurium ATCC13311, Staph. aureus CMCC 26003, and E. coli O157:H7, and L. monocytogenes CMCC54007), with maximum halo $(0.33 \mathrm{~cm})$ on $P$. aeruginosa MCC10104 and minimum halo $(0.13 \mathrm{~cm})$ on B. cereus ATCC14579. In a similar study, Lb. plantarum was found to inhibit Sal. typhimurium, Staph. aureus, E. coli O157:H7, and L. monocytogenes, with a maximum halo of $0.21 \mathrm{~cm}$ on L. monocytogenes and minimum halo of $0.08 \mathrm{~cm}$ on Staph. aureus (Li et al., 2015). Considering that antagonistic effects of Lb. plantarumWLPL04 might be different in vitro and in vivo, we assayed competition, inhibition, and displacement to ascertain the antiadhesion properties of $L b$. plantarum WLPL04 against E. coli O157:H7, Sal. typhimurium ATCC13311, and Staph. aureus CMCC26003. We found that adhesion of all pathogens on Caco-2 could be inhibited by Lb. plantarum WLPL04. Both E. coli O157:H7 and Staph. aureus CMCC26003 showed the same inhibition style; namely, the ideal inhibition strategy was displacement by Lb. plantarum WLPL04, whereas for Sal. typhimurium ATCC13311, the ideal inhibition strategy was preincubation of $L b$. plantarum WLPL04 before adding that pathogen. These results suggested that probiotics might present different antagonistic mechanisms against pathogens. Similar to our work, $L b$. plantarum CLC17 was shown to reduce the attachment of E. coli on Caco-2 cell line by competition, inhibition, and displacement, but displacement was the ideal strategy (García-Ruiz et al., 2014). Dhanani et al. (2011) reported that Lb. plantarum CS24.2 achieved reduction of adhesion of E. coli on Caco-2 cells by displacement (53\%), competition (41\%), and inhibition $(2.5 \%)$, which is similar to our findings for E. coli. In contrast, Lb. plantarum CS24.2 resulted in a reduction of adhesion ratio for Sal. typhimurium on Caco-2 cells in the order displacement (87\%), competition $(56 \%)$, and inhibition (17.4\%), which is different from our finding for Sal. typhimurium. One explanation for this discrepancy might be that strains of $L b$. plantarum from different resources have different specificities against different pathogens (Dhanani et al., 2011; García-Ruiz et al., 2014). It was proposed that competition between lactobacilli and pathogens was due to steric hindrance and the relative position of the hydrophobic surface and adhesion receptors (Lee and Puong, 2002). Currently, several reports note that the antagonistic effect of probiotics against pathogens might be relevant to adhesion factors (e.g., elongation factor Tu, EF-Tu), antimicrobial compounds (e.g., lactic acid, carbon dioxide, and bacteriocins), or completion for for the same adhesion receptors (Liévin et al., 2000; Šušković et al., 2010; Abedi et al., 2013).

Based on the high survival ratio in simulated GIT and challenge with 3 pathogens, we further determined that Lb. plantarum WLPL04 protected Caco-2 cells from acute inflammatory damage caused by SDS, which might be associated with antioxidant substances such as EPS. In our previous study, we confirmed that EPS yielded by $L b$. plantarum R315 exhibited a stronger antioxidant effect in vitro compared with bifidobacteria (Li et al., 2014b). Considering that little information has been reported about the antiinflammatory effect of Lb. plantarum on Caco-2 cells, and Sal. typhimurium is a common pathogen yielding LPS, which induces the inflammatory reaction of epithelial cells, we tested the antiinflammatory potential of $L b$. plantarum WLPL04 by monitoring the inflammatory response of Caco-2 cells. We found that expression of the antiinflammatory cytokine IL-10 was increased and expression of proinflammatory cytokines (IL-6, IL-8, and TNF- $\alpha$ ) induced by Sal. typhimurium was significantly decreased $(P<$ 0.01 ), suggesting a potential antiinflammatory property of Lb. plantarum WLPL04. Overall, our results are in agreement with previous works (Frick et al., 2007; Candela et al., 2008), which reported that commensal bacteria may protect intestinal epithelial cells from enteropathogens by inhibiting IL-8 production, which is involved in epithelial cell injury. 


\section{CONCLUSIONS}

To our knowledge, this is the first report to study the antagonistic effect of $L b$. plantarum against 3 pathogens via competition, inhibition, and displacement strategies, and to report the antiinflammatory effect on Caco-2 cells on the mRNA level. Lactobacillus plantarum WLPL04 exhibited strong antimicrobial activity against various pathogens, survived well in simulated gastrointestinal tract, and yielded a high amount of EPS. Together with the antibiotic sensitivity results and antiadhesion and antiinflammatory properties against pathogens, our results indicate that $L b$. plantarum WLPL04 from breast milk might be a suitable candidate probiotic for promoting host health.

\section{ACKNOWLEDGMENTS}

The authors are grateful for the contributions of Mingfan Pan (School of Life Sciences, Nanchang University, Nanchang, P. R. China.) and Renhui Huang (State Key Laboratory of Food Science and Technology, Nanchang University, Nanchang, P. R. China) on discussion of the results. This project was sponsored by the China Postdoctoral Science Foundation (Beijing, China; grant no. 2015M570567), Jiangxi Province Postdoctoral Science Foundation (Jiangxi, China; grant no. 2014KY07), and National Natural Science Foundation of China (Beijing, China; NSF 31170091, 31360377 and 31260363).

\section{REFERENCES}

Abedi, D., S. Feizizadeh, V. Akbari, and A. Jafarian-Dehkordi. 2013. In vitro anti-bacterial and anti-adherence effects of Lactobacillus delbrueckii subsp bulgaricus on Escherichia coli. Res. Pharm. Sci. $8: 260-268$.

Albesharat, R., M. A. Ehrmann, M. Korakli, S. Yazaji, and R. F. Vogel. 2011. Phenotypic and genotypic analyses of lactic acid bacteria in local fermented food, breast milk and faeces of mothers and their babies. Syst. Appl. Microbiol. 34:148-155.

Arroyo, R., V. Martin, A. Maldonado, E. Jimenez, L. Fernandez, and J. M. Rodriguez. 2010. Treatment of infectious mastitis during lactation: antibiotics versus oral administration of lactobacilli isolated from breast milk. Clin. Infect. Dis. 50:1551-1558.

Bermudez-Brito, M., S. Muñoz-Quezada, C. Gómez-Llorente, E. Matencio, F. Romero, and A. Gil. 2015. Lactobacillus paracasei CNCM I-4034 and its culture supernatant modulate Salmonellainduced inflammation in a novel transwell co-culture of human intestinal-like dendritic and Caco-2 cells. BMC Microbiol. 15:79.

Candela, M., F. Perna, P. Carnevali, B. Vitali, R. Ciati, P. Gionchetti, F. Rizzello, M. Campieri, and P. Brigidi. 2008. Interaction of probiotic Lactobacillus and Bifidobacterium strains with human intestinal epithelial cells: adhesion properties, competition against enteropathogens and modulation of IL-8 production. Int. J. Food Microbiol. 125:286-292.

Chen, T., Q. Wu, S. Li, S. Xiong, S. Jiang, Q. Tan, Z. Zhang, D. Zhu, and H. Wei. 2014. Microbiological quality and characteristics of probiotic products in China. J. Sci. Food Agric. 94:131-138.

da Silva Sabo, S., M. Vitolo, J. M. D. González, and R. P. de Souza Oliveira. 2014. Overview of Lactobacillus plantarum as a promising bacteriocin producer among lactic acid bacteria. Food Res. Int. 64:527-536.

Dhanani, A. S., S. B. Gaudana, and T. Bagchi. 2011. The ability of Lactobacillus adhesin EF-Tu to interfere with pathogen adhesion. Eur. Food Res. Technol. 232:777-785.

Díaz-Ropero, M. P., R. Martin, S. Sierra, F. Lara-Villoslada, J. M. Rodriguez, J. Xaus, and M. Olivares. 2007. Two Lactobacillus strains, isolated from breast milk, differently modulate the immune response. J. Appl. Microbiol. 102:337-343.

Dubois, M., K. A. Gilles, J. K. Hamilton, P. Rebers, and F. Smith. 1956. Colorimetric method for determination of sugars and related substances. Anal. Chem. 28:350-356.

Feng, Y., J. Gong, H. Yu, Y. Jin, J. Zhu, and Y. Han. 2010. Identification of changes in the composition of ileal bacterial microbiota of broiler chickens infected with Clostridium perfringens. Vet. Microbiol. 140:116-121.

Finamore, A., M. Roselli, A. Imbinto, J. Seeboth, I. P. Oswald, and E. Mengheri. 2014. Lactobacillus amylovorus inhibits the TLR 4 inflammatory signaling triggered by enterotoxigenic Escherichia coli via modulation of the negative regulators and involvement of TLR2 in intestinal Caco-2 cells and pig explants. PLoS ONE 9:e94891.

Frick, J. S., K. Schenk, M. Quitadamo, F. Kahl, M. Koberle, E. Bohn, M. Aepfelbacher, and I. B. Autenrieth. 2007. Lactobacillus fermentum attenuates the proinflammatory effect of Yersinia enterocolitica on human epithelial cells. Inflamm. Bowel Dis. 13:83-90.

García-Ruiz, A., D. G. de Llano, A. Esteban-Fernández, T. Requena, B. Bartolome, and M. V. Moreno-Arribas. 2014. Assessment of probiotic properties in lactic acid bacteria isolated from wine. Food Microbiol. 44:220-225.

Huang, R., X. Tao, C. Wan, S. Li, H. Xu, F. Xu, N. P. Shah, and H. Wei. 2015. In vitro probiotic characteristics of Lactobacillus plantarum ZDY 2013 and its modulatory effect on gut microbiota of mice. J. Dairy Sci. 98:5850-5861.

Jankovic, I., W. Sybesma, P. Phothirath, E. Ananta, and A. Mercenier. 2010. Application of probiotics in food products - Challenges and new approaches. Curr. Opin. Biotechnol. 21:175-181.

Kwak, S.-H., Y.-M. Cho, G.-M. Noh, and A.-S. Om. 2014. Cancer preventive potential of kimchi lactic acid bacteria (Weissella cibaria, Lactobacillus plantarum). J. Cancer Prev. 19:253.

Lara-Villoslada, F., M. Olivares, S. Sierra, J. M. Rodriguez, J. Boza, and J. Xaus. 2007. Beneficial effects of probiotic bacteria isolated from breast milk. Br. J. Nutr. 98(Suppl 1):S96-S100.

Lee, H. A., Y.-J. Bong, H. Kim, J.-K. Jeong, H.-Y. Kim, K.-W. Lee, and K.-Y. Park. 2015. Effect of nanometric Lactobacillus plantarum in kimchi on dextran sulfate sodium-induced colitis in mice. J. Med. Food 18:1073-1080.

Lee, Y.-K., and K.-Y. Puong. 2002. Competition for adhesion between probiotics and human gastrointestinal pathogens in the presence of carbohydrate. Br. J. Nutr. 88(Suppl 1):S101-S108.

Li, C., Y. Chen, L.-Y. Kwok, X. Chen, H. Yu, H. Yang, J. Yang, J. Xue, T. Sun, and H. Zhang. 2015. Identification of potential probiotic Lactobacillus plantarum isolates with broad-spectrum antibacterial activity. Dairy Sci. Technol. 95:381-392.

Li, S., T. Chen, F. Xu, S. Dong, H. Xu, Y. Xiong, and H. Wei. 2014a. The beneficial effect of exopolysaccharides from Bifidobacterium bifidum WBIN03 on microbial diversity in mouse intestine. J. Sci. Food Agric. 94:256-264.

Li, S., R. Huang, N. P. Shah, X. Tao, Y. Xiong, and H. Wei. 2014b. Antioxidant and antibacterial activities of exopolysaccharides from Bifidobacterium bifidum WBIN03 and Lactobacillus plantarum R315. J. Dairy Sci. 97:7334-7343.

Liévin, V.. I. Peiffer, S. Hudault, F. Rochat, D. Brassart, J. Neeser, and A. Servin. 2000. Bifidobacterium strains from resident infant human gastrointestinal microflora exert antimicrobial activity. Gut 47:646-652.

Maldonado, J., F. Lara-Villoslada, S. Sierra, L. Sempere, M. Gomez, J. M. Rodriguez, J. Boza, J. Xaus, and M. Olivares. 2010. Safety and tolerance of the human milk probiotic strain Lactobacillus salivarius CECT5713 in 6-month-old children. Nutrition 26:1082-1087. 
Martín, R., S. Langa, C Reviriego, E Jimenez, M. L. Marin, J. Xaus, L. Fernandez, and J. M. Rodriguez. 2003. Human milk is a source of lactic acid bacteria for the infant gut. J. Pediatr. 143:754-758.

Mileti, E., G. Matteoli, I. D. Iliev, and M. Rescigno. 2009. Comparison of the immunomodulatory properties of three probiotic strains of Lactobacilli using complex culture systems: Prediction for in vivo efficacy. PLoS ONE 4:e7056.

Nikolic, M., P. López, I. Strahinic, A. Suárez, M. Kojic, M. Fernández-García, L. Topisirovic, N. Golic, and P. Ruas-Madiedo. 2012. Characterisation of the exopolysaccharide (EPS)-producing Lactobacillus paraplantarum BGCG11 and its non-EPS producing derivative strains as potential probiotics. Int. J. Food Microbiol. 158:155-162.

Olivares, M., M. P. Diaz-Ropero, R. Martin, J. M. Rodriguez, and J. Xaus. 2006. Antimicrobial potential of four Lactobacillus strains isolated from breast milk. J. Appl. Microbiol. 101:72-79.

Olivares, M., M. P. Diaz-Ropero, S. Sierra, F. Lara-Villoslada, J. Fonolla, M. Navas, J. M. Rodriguez, and J. Xaus. 2007. Oral intake of Lactobacillus fermentum CECT5716 enhances the effects of influenza vaccination. Nutrition 23:254-260.

Parvez, S., K. Malik, S. Ah Kang, and H. Y. Kim. 2006. Probiotics and their fermented food products are beneficial for health. J. Appl. Microbiol. 100:1171-1185.
Presti, I., G. D'Orazio, M. Labra, B. La Ferla, V. Mezzasalma, G. Bizzaro, S. Giardina, A. Michelotti, F. Tursi, and M. Vassallo. 2015 Evaluation of the probiotic properties of new Lactobacillus and Bifidobacterium strains and their in vitro effect. Appl. Microbiol. Biotechnol. 99:5613-5626.

Solís, G., C. G. de Los Reyes-Gavilan, N. Fernandez, A. Margolles, and M. Gueimonde. 2010. Establishment and development of lactic acid bacteria and Bifidobacteria microbiota in breast-milk and the infant gut. Anaerobe 16:307-310.

Šušković, J., B. Kos, J. Beganović, A. Leboš Pavunc, K. Habjanič, and S. Matošić. 2010. Antimicrobial activity-The most important property of probiotic and starter lactic acid bacteria. Food Technol. Biotechnol. 48:296-307.

Tan, Q., H. Xu, Z. P. Aguilar, S. Peng, S. Dong, B. Wang, P. Li, T. Chen, F. Xu, and H. Wei. 2013. Safety assessment and probiotic evaluation of Enterococcus faecium YF5 isolated from sourdough. J. Food Sci. 78:M587-M593.

Zago, M., M. E. Fornasari, D. Carminati, P. Burns, V. Suàrez, G Vinderola, J. Reinheimer, and G. Giraffa. 2011. Characterization and probiotic potential of Lactobacillus plantarum strains isolated from cheeses. Food Microbiol. 28:1033-1040. 